\title{
Dilemas e desafios da modernidade
}

\author{
EDUARDO PORTELLA
}

$\mathrm{O}$

S DESAFIOS brasileiros prosseguem, em meio a dilemas mais ou menos persistentes. $\mathrm{O}$ que acontecera com a promessa de progresso, ou com os programas de desenvolvimento, repete-se agora, guardadas as indevidas proporções, com o compromisso modernizador. Essas referências foram postas no mercado com defeitos de fabricação, ao que tudo indica de difíceis consertos. A primeira, a idéia de progresso, nascida sob o patrocínio da racionalidade unânime, pecou por excesso de confiança. Sobretudo de confiança em si mesma. A segunda jamais conseguiu integrar os seus elementos constitutivos. Acrescentou ao seu nome, sobrenomes diversos: social, durável, sustentável. Não mudou muito o curso do desenvolvimento no mundo dos despossuídos. Em algumas geografias as coisas vieram a piorar. A modernidade, tão ambiciosa quanto facciosa, chega até nós estressada, precocemente extenuada, sacudida pelas turbulências da pós-modernidade ou, como prefiro chamar, da baixa modernidade. Talvez devamos insistir em falar de modernidade no plural.

O desafio mais radical continua sendo a questão da desigualdade. Uma história simples, e cada vez mais monótona e insuportável: poucos com muito, e muitos com muito pouco. A meta da eqüidade se nos afigura distante, e a separação de modernidade econômica e modernidade política vem se acentuando, deixando pouca margem para o progresso também designado de social. Com isso é possível ler, no eletroencefalograma da sociedade brasileira arrítmica, a fragilização da classe média, a desorganização dos assalariados e dos sem carteira assinada, o aumento da exclusão, e a ansiedade da nãoinclusão. É um problema transnacional, que se distingue, aqui e ali, por traços específicos. Na turbulenta Espanha de hoje, o governo José Maria Aznar reelegeu-se passando a imagem de honradez e competência para gerar emprego. O debate ideológico quase desaparece, e as cobranças passam a ser outras. O discurso de campanha do presidente eleito do México, Vicente Fox, optou, em boa parte, por essa pauta programática.

É que, com a debilitação, ou o desaparecimento do debate ideológico, bem como com o agravamento dos itens de subsistência e sobrevivência, as 
questões pontuais ganharam novo corpo e nova alma. Ou perderam o corpo e não ganharam a alma. Vai ficando igualmente para trás o protocolo do capitalismo social, que a versão britânica da globalização abrigou confiantemente, mesmo à revelia da Comunidade Européia. A economia global vem sendo, pelo menos até aqui e até segunda ordem, um mecanismo redutor a serviço da desigualdade. Por isso todo e qualquer projeto democrático, republicano e transformador, nunca deve deixar de levar em conta a incompatibilidade visceral entre fundamentalismo de mercado - que é bem diferente do que se conhece como democracia de mercado - e justiça social - onde o Estado desempenha papel crucial. Não basta ampliar as oportunidades; é preciso redistribuir as recompensas. A globalização, pelo que consigo enxergar, mantém os ouvidos surdos a essas percepções.

Não creio que a democracia legítima possa fazer da indiferença, ou do abandono, o seu modelo de comportamento. Tão pouco acredito que a autoajuda, transbordante na literatura de massa, possa substituir, em qualquer parcela, os deveres de solidariedade.

Antes de mais nada cabe, prioritariamente, alargar os espaços de legitimidade da nossa inconstante democracia, corrigir o déficit político, a carência do desempenho qualificado. Falta uma agenda política plantada, legal e legítima. Não se trata de produzir um projeto acabado, um pacote fechado, provavelmente imóvel, refratário à riqueza dos dissensos. Trata-se de administrar criativamente suspeitas infundadas, obsessões anacrônicas, e apostar na diversidade, nos intercâmbios materiais e

falta uma agenda política plantada, legal e legítima... imateriais. Esse vazio só deverá ser preenchido pela reforma política atualizada, concebida longe das próteses partidárias, das hipotecas eleitoreiras, dos sufrágios adulterados, de todas essas velhas patologias que fizeram não digo história porém estória, no Brasil contemporâneo. Em data não muito remota. O factóide constitucional de 88 não soube evitar essa ancestralidade perversa.

Sem legitimidade democrática, o avanço emancipatório fica comprometido. O ex-futuro "país do futuro" se vê mais uma vez protelado. Até quando? Apesar do muito que se fez, apesar dos caminhos já percorridos, a democracia brasileira ainda tem muita estrada pela frente. E nessas horas, até a construção do Estado de direito não escapa aos questionamentos mais freqüentes. A insuficiência normativa, e a inoperância e o encastelamento da máquina jurídico-institucional, se juntam a esse quadro adverso. 
Voltamos ainda à exigência inadiável de reprogramação do Estado envolvendo, evidentemente, as condições de seu financiamento. Que não pode ser bancado pela nossa coleção de dívidas. Aliás, a justa preocupação com a nossa dívida externa nem sempre se faz acompanhar de igual cuidado com o endividamento público interno. Até porque os parceiros nacionais, alimentados pelos interesses particulares de uma federação incipiente, em vez de verem a floresta, apenas vêem as árvores. A tributação deve incidir sobre sócios mais ou menos relapsos, e não tanto sobre a produção e o trabalho. O que só ocorrerá em um Estado nem avarento nem filantrópico, porém criteriosamente regulador. Distante, bem distante, do princípio tecnocrático do tratamento indiferenciado, ou do corte horizontal que, na quase totalidade dos casos, vem a ser falso e inoperante a uma só vez.

É verdade que toda essa controvérsia se instalou no centro descentrado do espaço público, e vem sendo regida especialmente pela mídia eletrônica. "Teremos de nos contentar - afirma Peter Sloterdijk - em delimitar os estágios da paleopolítica, da política clássica e da hiperpolítica" (No mesmo barco). A hiperpolítica, virtual sem ser virtuosa, adquiriu foros de instância formadora de opinião. E tem conseguido resultados surpreendentes. Sobretudo em termos de produção de verdades nunca antes imaginadas, em geral sob os auspícios de um regime de emagrecimento intelectual extremamente severo. Mas a anorexia intelectual do espaço público em tempos de globalização pode ser compensada ou, melhor dito, sanada? Não sei se a medicina cultural dispõe de algum medicamento para essa disfunção. Em qualquer hipótese, ainda não foi posto à venda. Nem por isso o espaço público deixou de expandir-se.

Fica contudo difícil ignorar o lado relevante da mídia de massa, o caráter de serviço público que igualmente desdobra. Apesar de derrapagens graves, no exercício de paranóias persecutórias ou submetida ao papel cinematográfico do justiceiro, a imprensa vem apontando, por todas as partes do mundo, os desvios do poder, as transgressões da cidadania, a corrupção de variados tipos, não raro a fraude eleitoral estranhamente instalada em meio à precisão eletrônica. A responsabilidade penal de tiranos impiedosos e de gestores públicos inescrupulosos jamais teria alcançado a ressonância mundial que adquiriu, e exercido a decorrente pressão política, sem o concurso tenaz das imagens em rede, distribuídas a cada minuto, criando inesperados atores sociais. Isto significa que, dispondo da base legal requerida, da legitimidade necessária, o direito à imagem estará em condições de conferir à democracia a consistência almejada. 
A impressão que se tem é a de que o trabalho da elaboração de indicadores qualitativos foi deixado à margem da história. Por políticos apressados, por tecnocratas amnésicos ou por intelectuais desfibrados. Ou pelos três ao mesmo tempo. Da concepção apenas patrimonialista da cultura, toda dobrada sobre a apologia do passado, dos guardiães do templo até os vândalos dos estádios ou cultores do heavy-metal, da cultura popular à cultura de massa, resumida no folhetim eletrônico, muito ficou por fazer En attendant Godot. Essa espera piedosa ou desolada desvirtuou-se na voragem do apocalypse now, à procura do sentido perdido. Quando o que cabia fazer era substituir os aparelhos de navegação, por outros mais flexíveis e confluentes.

Os programas pedagógicos dominantes tomaram outros rumos. Em vez de devolver os valores à história, optaram, na sua grande parte, por decretar a falência da história, em espetáculo público de triste memória. Implantaram, ou transplantaram a performance, no lugar que estaria reservado à invenção da qualidade. A apologia performática se tornou o estágio mais avançado, e

\section{ב progrediu \\ o que denominei de educação sem cultura...} mais reducionista, da meritocracia invertebrada. O perito representaria a estupidez da gestão recessiva, como meio sem fim. O aumento sem precedente, e sem justificativa técnica, correspondia à prevalência da racionalidade econômica. A partir daí “a pedagogia bancária” passou a mandar e desmandar. A perspectiva econômico-monetária é, quando muito, historiográfica. O que é, convenhamos, muito pouco. A sociedade do conhecimento foi lançada nas perigosas autopistas do ciberespaço, sem as indispensáveis proteções reflexivas. Progrediu, inquietantemente, o que denominei de educação sem cultura. As transformações certamente verificadas devem-se antes à comunicação midiática do que à formação escolar. Esta preserva, com comovente ardor e discreto ânimo transformador, as formas habituais de sociabilização.

Por isso não encontro razões maiores para alterar uma velha inclinação. Inclino-me a supor que a educação é um privilegiado mecanismo de transmissão cultural. Em uma sociedade de massa, veloz e rasante, registra-se insuportável insuficiência quantitativa. Logo, deparamo-nos com duas modalidades de escassez - uma quantitativa, outra qualitativa; uma menos outra mais. Com isso preservo-me da euforia iluminista e, embora continue a nela depositar teimosas esperanças, jamais lhe confiro poderes ilimitados. A educação pode bastante; não pode o suficiente.

Quando as ofertas quantitativas desatendem ao crescimento da demanda, mesmo que a bússola estatística seja promissora, os efeitos serão pouco estimulantes. Isto sem avaliar ainda os possíveis progressos qualitativos. O 
que é primordial. Mesmo que a sociedade seja de massa, e que, segundo a tolerância de alguns, as exigências qualitativas sejam menores, torna-se impossível aceitar e conformar-se, com a proscrição da qualidade. É certo que esse problema vem de longe, e em dias já remotos cheguei a anunciar, e talvez a formular, "a pedagogia da qualidade". Não posso dizer que avancei, ou que avançamos, na proporção do tempo decorrido. É provável até que tenhamos regredido. Porque priorizou-se o ensino voltado para o desempenho, estreitamente performático, dirigido à produção de peritos, em detrimento da educação sustentada por valores. Entre o perito, competente a qualquer preço, e o cidadão, socialmente encarnado, parece que nunca vacilamos; ficamos sempre com o primeiro. Por outro lado cultivamos a tendência a associar qualidade e abstração - utensílio ou objeto não identificado, e por isso mesmo de uso restrito. O resto ficou por conta das viagens de passeio nos céus de brigadeiro da meritocracia. A nação escondida, abafada, não raro silenciada pelos dispositivos de segregação das elites avaras, ficou para mais adiante. Só que o mais adiante veio a ser a mundialização.

Ainda não ficaram muito nítidos os níveis de compatibilidade entre democracia e globalização, sobretudo nos domínios da economia e do social. Com o capital político operando no vermelho, a desigualdade ostensiva, a tênue vocação federativa paralisada, urge reforçar a governabilidade, infundindo energias novas na vontade deliberativa. O que somente é possível pelo alargamento do horizonte da legitimidade, pela compreensão matizada da dinâmica da intersubjetividade. É que, de há muito cessado o reinado do ator principal, protagonista insolente e solitário, a cena plurifocal da política tardo-moderna reúne papéis para todos os gostos, para todos os perfis de intérpretes. A exigência maior, o traço diferenciador, será a capacidade negociadora, fonte e força da legitimidade. O Estado criteriosamente regulador, antes voltado para as pessoas do que para as coisas, estará fundado no interesse coletivo, e na ética do serviço público. Será cosmopolita, sim; porém interativo, equânime, responsável.

O crescente processo de internacionalização, a irrupção vertiginosa das redes de comunicação, vai criando um novo internacionalismo, com repercussões intimidativas e/ou promissoras, em todos os campos da ação humana, e nas mais diversificadas geografias. A tal ponto que Paul Virílio já começa a vaticinar "a morte da geografia". É que as relações fomentadas pelo poder globalizado, e implementadas pela internetização, trazem dentro de si um sofisticado aparelho de desterritorialização - alguma coisa como um imprevisível marca-passo da história. Resta saber se esse novo internacionalismo, 
meio desequilibrado na corda-bamba da globalização, operará em íntima sintonia com os organismos multilaterais, especialmente os que integram o Sistema das Nações Unidas. Os abalos sísmicos promovidos pelos mercados financeiros, não só arruinaram ou terrorizaram economias indefesas, como generalizaram a desconfiança que nunca deixou de existir. Tudo indica que o compromisso internacional das democracias nacionais terá de ser renegociado por Estados pós-nacionais. Vem daí grande parte da resistência com que se defronta a agenda da globalização. Seria ela a tábula rasa, a amnésia forçada, a queima de arquivos, o decurso de prazo do nacional? Para onde vamos? Os prognósticos a que nos entregamos nas últimas décadas revelaram-se altamente dissociativos. E nos atiraram nos braços de uma futurologia fraudulenta. Já é tempo de parar para pensar. Porém sem mais delongas.

Eduardo Portella, ensaísta, é professor emérito da Universidade Federal do Rio de Janeiro e membro da Academia Brasileira de Letras. Escreveu, entre outros, os livros Dimensões I (1958), Teoria da Comunicação Literária (1963) e O intelectual e o poder (1983). 